\title{
Konflik Kepentingan dalam Profesi Dokter
}

\author{
Rianto Setiabudy ${ }^{1,2}$, Julitasari Sundoro ${ }^{\mathrm{I}, 3}$ \\ ${ }^{\mathrm{I}}$ Majelis Kehormatan Etik Kedokteran Pengurus Besar Ikatan Dokter Indonesia \\ ${ }^{2}$ Departemen Farmakologi Fakultas Kedokteran Universitas Indonesia, Jakarta \\ ${ }_{3}^{3}$ The Indonesian Technical Advisory Group on Immunization Communicable Disease Control (ITAGI CDC)
}

\author{
Kata Kunci \\ dokter, disdaimer, etika, kepentingan, \\ konflik \\ Korespondensi \\ contact@ilmiah.id \\ Publikasi \\ (C) 2019 JEKI/ilmiah.id \\ DOI \\ I0.26880/jeki.v3ir.28 \\ Tanggal masuk: ${ }_{5}$ Oktober 2018 \\ Tanggal ditelaah: 12 Januari 2019 \\ Tanggal diterima: 17 Januari 2019 \\ Tanggal publikasi: 26 Februari 2019
}

\begin{abstract}
Abstrak Sebagaimana halnya dengan pekerjaan profesional lainnya, dokter juga sering terpapar terhadap masalah konflik kepentingan (KK) dalam pekerjaannya sehari-hari. Ada banyak contoh pelanggaran etika oleh dokter yang timbul akibat masalah $\mathrm{KK}$ ini. Sebagian dilakukan dengan kesengajaan, sebagian lagi dilakukan tanpa sadar seolah-olah perilaku itu adalah sesuatu yang biasa dilakukan dan tidak ada yang salah dengan itu. Setidaknya ada dua pasal dalam Kode Etik Kedokteran Indonesia (KODEKI) yang memberi rambu etika terkait masalah $\mathrm{KK}$ ini. Untuk menghindarkan dampak negatif $\mathrm{KK}$ ini ada beberapa tindakan yang dapat dikerjakan, antara lain penghindaran yang menyeluruh, pengungkapan, pengambilan sikap netral, dan penggunaan bantuan pihak luar.
\end{abstract}

Abstract Like the other professionals, doctors are frequently exposed to the problem of conflict of interest (COI) in their daily job. There are ample of ethical violation examples done by the doctors related to this issue. Some of them are conducted intentionally, but some are not because these violations are so commonly done that it they are no longer recognized as ethical violations. In the Indonesian Ethical Codes (KODEKI) at least there are two articles giving guidelines related to the issues of COI. To avoid the negative impact of $\mathrm{COI}$ there are some preventive measures to be executed, which include total avoidance, disclosure, recusal, and seeking assistance of an independent body.

Konflik Kepentingan (conflict of interest) adalah masalah yang melekat dalam pekerjaan sehari-hari dalam kehidupan sehari para profesional, termasuk dokter. Masalah ini juga melekat pada pemegang kekuasaan misalnya anggota DPR, camat, lurah, polisi, badan pengawas pemilihan umum, dll. Khusus untuk bidang kesehatan, yang banyak menghadapi masalah Konflik Kepentingan (KK) ialah dokter yang memiliki kekuasaan untuk memutuskan kebijakan publik, key opinion leaders, direktur rumah sakit, kepala bagian pembelian, dsb.

Di negara-negara maju masalah KK selalu disoroti dengan teliti dan sedapat mungkin dijauhi. Di Indonesia masalah ini masih kurang mendapat perhatian. Banyak dokter yang malah tidak merasakan adanya pelanggaran etika ketika mereka melakukan perbuatan tidak terpuji terkait masalah $\mathrm{KK}$ ini.

\section{Pemahaman mengenai Konflik Kepentingan}

KK adalah suatu keadaan di mana seorang profesional (atau pejabat) yang mempunyai kewajiban primer (primary interest) -yaitu bahwa ia harus menjalankan kewajibannya secara baik, adil, dan jujur - dalam kondisi tertentu melalaikan kewajibannya itu karena adanya pengaruh dari luar, yaitu adanya kepentingan sekunder (secondary interest). ${ }^{1}$

Kepentingan sekunder biasanya berkaitan dengan adanya keuntungan pribadi. Profesi dokter pun tidak luput dari masalah semacam ini, apalagi bila dokter yang bersangkutan dipercaya memangku jabatan yang penting, misalnya direktur rumah sakit, anggota tim untuk pembelian obat rumah sakit, renovasi rumah sakit, pengadaan alat laboratorium, pembelian alat radioterapi, dll. Profesionalisme bertumpu pada dua pilar yaitu judgment dan integritas. Kedua pilar ini dapat dirusak oleh $\mathrm{KK}$, bias, dan ketidakjujuran. ${ }^{2}$ 


\section{Dampak Negatif dari Konflik Kepentingan}

Adanya KK sebenarnya belum berarti telah terjadi suatu pelanggaran atau tindak pidana, namun KK itu terletak amat dekat dengan perbuatan tidak terpuji sehingga dewasa ini di negara-negara maju KK dianggap sebagai masalah serius yang harus dihindari. Dua tahun yang lalu seorang dokter (yang juga dosen) yang bekerja di suatu Fakultas Kedokteran negeri ternama di Jakarta ditugaskan institusinya mengurusi program pendidikan mahasiswa di suatu fakultas kedokteran di Papua. Semuanya ini adalah dalam rangka program pengampuan. Ketika menjalankan tugasnya di Papua itu, dosen itu saling jatuh cinta dengan salah satu mahasiswinya. Untuk mengambil hati, dosen itu membocorkan soal-soal ujian kepada pacarnya itu. Perbuatan yang tidak terpuji ini kemudian terungkap dan berakhir dengan pencopotan tugas dosen yang bersangkutan karena ia telah gagal menjalankan tugas profesionalnya sebagai dosen. Contoh ini terjadi akibat adanya konflik kepentingan.

Contoh lain menyangkut promosi suatu obat golongan bifosfonat untuk mengatasi osteoporosis di suatu RS besar di wilayah Tangerang. Dalam promosi itu dijanjikan bahwa setiap dokter yang meresepkan suatu obat golongan bifosfonat sampai mencapai target tertentu akan dapat ikut wisata gratis ke Thailand. Dampaknya luar biasa karena pemberian resep produk bifosfonat tersebut lalu melonjak hebat dalam waktu dua bulan, padahal kasus osteoporosis tidak bertambah. Persediaan obat itu di apotek RS habis dalam waktu hanya beberapa hari sehingga harus segera dipesan lagi. Namun ketika wisata sudah selesai, banyak obat itu mengendap di apotek menjadi dead stock karena tidak ada lagi dokter yang meresepkannya. Fenomena ini jelas menunjukkan bahwa lonjakan frekuensi pemberian resep yang terjadi selama 2 bulan itu terjadi sebagai akibat KK.

\section{Beberapa Contoh KK pada Profesi Dokter}

1. Berbagai perhimpunan profesi sering harus menyusun konsensus atau guideline, atau clinical pathway mengenai penatalaksanaan penyakit tertentu. Agar tidak terganggu oleh tugas sehari-hari, kegiatan ini biasanya diselenggarakan di luar kota. Seluruh anggota perhimpunan ini akan masuk ke dalam KK bila mereka mendapat bantuan tiket pesawat, biaya hotel, makan, wisata, suvenir, dll. Sponsor biasanya berminat memberi dana untuk kegiatan seperti ini karena mereka berharap agar obatnya masuk dalam tatalaksana penyakit terkait. Praktik ini akan menjadi yang lebih buruk lagi ialah ketika dokter mau menggunakan draft guideline yang disusun oleh industri farmasi yang mensponsori pertemuan itu

2. Seorang dokter berkewajiban untuk memilih obat yang efektif, aman, bermutu, dan terjangkau untuk kepentingan pasiennya (primary interest). Namun karena menerima hadiah dari industri farmasi, pilihan obat untuk pasiennya akhirnya didasarkan kepada pabrik farmasi yang paling banyak memberi hadiah atau komisi. Praktik yang lebih buruk lagi terjadi bila bukan pabrik farmasi yang menawarkan hadiah, tapi dokternya yang menekan industri farmasi agar memberi hadiah.

Yang juga sangat meresahkan dari segi etika kedokteran ialah ketika seorang dokter ikut dalam kegiatan multi-level marketing (MLM) dalam praktiknya, maka ia akan memengaruhi pasien menggunakan produk suplemen makanan dll. yang harganya mahal namun khasiat dan keamanannya tidak jelas demi mendapatkan bonus lebih banyak. Bila dokter tersebut ikut MLM untuk dirinya sendiri tentu tidak ada masalah etika, namun ketika ia mengikut-sertakan pasiennya, maka ia melakukan perbuatan tidak terpuji akibat terjadinya KK.

3. Dokter yang bekerja di institusi pendidikan sering kali diminta menyajikan ceramah ilmiah mengenai pengobatan penyakit tertentu. Sebagai seorang ilmuwan ia mempunyai kewajiban primer untuk berbicara secara objektif. Namun ketika ia sudah menerima speaker fee dalam jumlah besar, atau berbagai macam hadiah lainnya dari sponsor, maka materi yang disajikan dalam presentasinya menjadi berat sebelah. Ia terlalu banyak memuji produk yang dibuat 
oleh sponsor, mengecilkan efek samping, atau sengaja menghapus bagian tertentu yang bisa mengurangi merugikan penjualan produk sponsornya. Praktik yang lebih buruk lagi ialah bila slides presentasinya pun dibuatkan oleh sponsor. Nama dagang yang seharusnya tidak boleh muncul dalam suatu presentasi ilmiah ternyata muncul berkalikali.

4. Dokter sangat dipercaya oleh masyarakat. Kata-katanya dianggap sebagai kebenaran yang tidak perlu disangsikan lagi. Karena itu seorang dokter yang ikut kegiatan promosi akibat dibayar oleh sponsor menimbulkan keprihatinan yang mendalam. Dewasa ini kita masih bisa melihat dokter yang ikut dalam siaran di radio maupun televisi yang mempromosikan kalung kesehatan, sabun mandi, air mineral, suplemen makanan, dan lain-lain. Keprihatinan ini makin mendalam ketika ia muncul dengan jas dokter, stetoskop, dll. Terkadang ia tidak menggunakan atribut dokter namun dalam percakapan ia dipanggil dengan sebutan "dokter".

5. Di dalam organisasi IDI, ada beberapa dokter yang menyandang gelar sarjana hukum. Banyak di antara mereka sangat dihormati oleh para dokter karena mau mendedikasikan pengetahuan mereka untuk menolong teman sejawat yang sedang terjerat kasus hukum. Namun di wilayah DKI pernah terjadi kasus di mana beberapa dokter dituduh polisi melakukan perbuatan melawan hukum, kemudian seorang dokter tertentu yang bergelar sarjana hukum tidak membantu sebagaimana layaknya yang diharapkan dari seorang petugas IDI. Ia malah menggiring para dokter yang sedang ketakutan itu ke kantor law firm yang ternyata adalah miliknya sendiri. Di sana dokter-dokter itu ditakut-takutinya dan dijanjikan akan dibela di pengadilan bila mau membayar biaya ratusan juta rupiah.

6. Dalam suatu sesi ilmiah di Muktamar IDI ke-30 yang berlangsung di Samarinda bulan Oktober 2018, ada seorang dokter yang memberi ceramah mengenai suatu penyedap makanan. Dalam ceramah itu ia tidak melakukan disclosure mengenai ada tidaknya masalah KK. Selain itu materi ceramah itu dirasakan kurang objektif karena seluruh materi presentasinya hanya mengutarakan segi positif dari penyedap masakan tersebut. Tidak ada disinggung mengenai dampak negatif potensial yang mungkin timbul. Seyogyanya dari seorang dokter diharapkan lahir informasi yang objektif, informatif, dan mampu menambah pengetahuan bagi pendengarnya. Penceramah harus dapat memberikan informasi secara berimbang.

Namun, ini hanyalah contoh kecil dari demikian banyaknya informasi bias yang muncul demikian banyak di berbagai acara ilmiah yang disponsori industri farmasi. Sering sekali terjadi semua slides yang disampaikan oleh penceramah dibuatkan oleh sponsor. Penceramah asing yang didatangkan sponsor dari luar negeri pun juga sering kali tidak berbicara objektif. Mereka biasanya tidak menyampaikan data dan fakta yang bisa mengurangi potensi penjualan produk terkait. Sering juga mereka tidak menyampaikan masalah disclosure mengenai KK. Dalam suatu penelitian yang dilakukan oleh Cherla et al, ${ }^{3}$ dilaporkan bahwa dalam laporan penelitian yang punya masalah KK, peneliti sering melaporkan hasil yang menguntungkan produk sponsor.

7. Amat sering terjadi ketika suatu RS akan merayakan ulang tahun, direkturnya (biasanya seorang dokter) mencari dana dengan menghubungi berapa industri farmasi. Pabrik yang mau menyumbang untuk acara ulang tahun itu diberi balas jasa oleh direktur dengan memasukkan produk obat-obat sponsor ke dalam daftar formularium RS yang bersangkutan. Walaupun tidak untuk kepentingan pribadinya, praktik seperti ini amat tidak etis karena mencari uang dengan masuk ke masalah KK. Sangat disayangkan bahwa praktik ini dilakukan secara rutin tiap tahun. Direkturnya pun tidak merasakan ada sesuatu yang salah dalam tindakan itu. Padahal dalam Peraturan Menteri Kesehatan No. 14 Tahun 2014 telah disebutkan bahwa pemberian uang, barang, 
rabat, komisi, pinjaman tanpa bunga, tiket perjalanan, fasilitas penginapan, perjalanan wisata, pengobatan cuma-cuma, dan fasilitas lainnya yang berhubungan dengan jabatan atau kewenangan tidak dibenarkan karena sudah termasuk tindak gratifikasi. ${ }^{4.5}$

\section{Apa yang Digariskan oleh KODEKI? ${ }^{6}$}

- Pasal 2:

"Seorang dokter harus senantiasa berupaya melaksanakan profesinya sesuai dengan standar profesi tertinggi”. Pasal ini menjelaskan bahwa standar profesi tertinggi harus diterapkan dalam pelayanan bagi pasien dan ini tidak boleh di-downgrade akibat dokter yang bersangkutan mau menerima hadiah yang tidak wajar.

- Pasal 3:

"Dalam melakukan pekerjaan kedokterannya, seorang dokter tidak boleh dipengaruhi oleh sesuatu yang mengakibatkan hilangnya kebebasan dan kemandirian profesi”. Senada dengan Pasal 2 tersebut di atas, pasal ini dengan jelas menjelaskan bahwa profesionalisme seorang dokter tidak boleh dicederai oleh faktor eksternal yang memberi keuntungan material bagi dokter yang bersangkutan atau kerabatnya.

\section{Bagaimana Mengurangi Dampak Negatif Konflik Kepentingan??}

1. Removal (penghindaran total)

Mekanisme ini adalah yang terbaik dan tersering digunakan orang yang menghadapi masalah KK. Misalnya, seorang dokter anggota MKEK di IDI yang diikutsertakan menangani kasus dugaan pelanggaran etika yang dilakukan oleh seorang dokter yang kebetulan adalah adiknya sendiri. Maka dalam kasus ini amat terpuji bila ia menolak ikut dalam divisi kemahkamahan untuk kasus tersebut. Dalam hal ini tentu ia harus menjelaskan alasan penolakannya itu.

Contoh lain ialah bila ada seorang dokter yang menjadi dosen dan pada suatu saat ia diminta menjadi anggota tim penyusun soal ujian. Anaknya kebetulan adalah mahasiswa yang akan ikut menempuh ujian tersebut.
Maka dalam hal ini ia wajib menolak tugas itu dengan menjelaskan alasannya.

2. Disclosure (pengungkapan)

Mekanisme ini digunakan bila mekanisme pertama di atas tidak dapat diterapkan. Misalnya, seorang dokter diminta memberi ceramah dalam suatu acara ilmiah mengenai suatu masalah medis yang menjadi bidang keahliannya. Acara ilmiah itu disponsori oleh suatu pabrik farmasi yang pernah mensponsori penceramah itu menghadiri suatu acara ilmiah di luar negeri. Dalam kasus ini ia tentu tidak perlu menggunakan mekanisme removal. Cukup bila ia menggunakan mekanisme disclosure dengan menjelaskan dalam slide presentasinya, detail bantuan apa saja yang pernah diterimanya dari pabrik obat terkait. Bila paparannya objektif, penghargaan orang terhadapnya tidak akan berkurang sedikitpun.

3. Recusal (abstain)

Ada kondisi tertentu di mana seseorang tidak bisa menarik diri dari kewajiban yang sudah melekat padanya (biasanya dalam kaitan tugas struktural). Maka ia ketika menghadapi masalah KK, ia bisa menggunakan mekanisme abstain ini. Sebagai contoh seorang dokter ditunjuk menjadi penanggung jawab renovasi rumah sakit. Dari lima perusahaan yang ikut tender, salah satunya ialah perusahaan yang dimiliki keluarganya. Maka dalam hal ini ia bisa tetap menjadi ketua tim terebut tapi sama sekali tidak ikut memutuskan perusahaan mana yang dipilih sebagai pemenang tender. Tugas ini diserahkan kepada anggota lain dalam tim yang tidak punya $\mathrm{KK}$.

4. Penggunaan pihak ketiga

Ketika seorang dokter harus membuat keputusan yang di mana terdapat kemungkinan besar dapat terjadi KK yang melibatkan bukan lagi individu, tapi tim secara keseluruhan maka sebaiknya digunakan pihak ketiga. Sebagai contoh, di suatu rumah sakit dibentuk tim menyusun formularium. Untuk ini dibentuk suatu tim. Ketika harus menentukan pilihan untuk obat anti diabetes, mereka melihat 
ada empat pilihan obat gliptin (sitagliptin, vildagliptin, saksagliptin, linagliptin). Para klinisi yang membutuhkan obat golongan ini ternyata berbeda pendapat mengenai obat mana yang harus dipilih. Tim penyusun formularium sendiri tidak yakin mana yang sebaiknya dipilih karena keterbatasan pengetahuan mereka. Maka dalam hal ini sebaiknya diminta pendapat pihak ketiga yang tidak punya $\mathrm{KK}$ dan mempunyai pengetahuan yang memadai untuk itu, misalnya bantuan tim yang memahami farmakologi klinik untuk membuat pilihan yang tepat dan bersih dari masalah KK.

Menurut Sloans, ${ }^{8}$ semuanya ini akhirnya ditentukan oleh pribadi seorang dokter: apakah ia mementingkan integritas dan kemuliaan profesinya atau ia lebih mengejar gratifikasi yang menguntungkan pribadinya. Hati nuraninya yang akan menentukan.

\section{KESIMPULAN}

Baik dari segi struktural maupun profesional, dokter sering kali menghadapi masalah KK. Di Indonesia masalah ini sering dianggap tidak penting, bahkan sering menyeret dokter melakukan perbuatan tidak terpuji. Yang lebih memprihatinkan lagi, banyak dokter yang memegang posisi pimpinan dalam institusinya, melakukan pelanggaran etika terkait KK tanpa menyadari bahwa perbuatan itu tercela. Dampak negatif akibat $\mathrm{KK}$ ini akhirnya harus dipikul oleh pasien dan masyarakat. Mereka sering harus membeli obat yang lebih mahal namun mutunya buruk, atau formularium rumah sakit mengikutsertakan obat-obat yang tidak bermanfaat.

\section{KONFLIK KEPENTINGAN}

Penulis tidak mempunyai konflik kepentingan dalam menulis artikel ini.

\section{UCAPAN TERIMA KASIH}

Penulis memberikan ucapan terima kasih kepada Fadlika Harinda yang telah membantu penulis dalam merealisasikan tulisan ini.

\section{REFERENSI}

1. Lichter AS. Conflict of interest and the integrity of the medical profession. JAMA. 2017;317(17):1725-6.

2. Stead WW. The complex and multifaceted aspects of conflicts of interest. JAMA 2017;317:1765-7.

3. Cherla DV, Viso CP, Holihan JL, Bernardi $\mathrm{K}$, Moses ML, Mueck KM et al. The effect of financial conflict of interest, disclosure status, and relevance on medical research from the US. J Gen Intern Med. 2019 Jan 2 (in press)

4. Peraturan Menteri Kesehatan Republik Indonesia Nomor 14 Tahun 2014 tentang Pengendalian Gratifikasi di Lingkungan Kementerian Kesehatan. 2014.

5. Santosa F, Permana MY, Baharuddin M. Sponsorship pendidikan kedokteran: batasan yang sering terabaikan. Jurnal Etika Kedokteran Indonesia. 2018;2(1):13-7. doi: 10.26880/jeki.v2i1.10.

6. Majelis Kehormatan Etik Kedokteran Indonesia. Kode etik kedokteran tahun 2012. Jakarta: Ikatan Dokter Indonesia; 2012.

7. Australian Medical Association Guidelines for Doctors on Managing Conflicts of Interest in Medicine 2018

8. Sloans ST. Inducement of pharmaceutical companies: the elephant in the room. Indian Paediatrics 2018:649-51. 